\title{
UMA ANÁLISE DA RELAÇÃO INDIVÍDUO E COLETIVIDADE SEGUNDO EDITH STEIN
}

\author{
Fabio Maia Sobral ${ }^{1}$ \\ Universidade Federal do Ceará (UFC) \\ (D) https://orcid.org/0000-0002-6638-5121 \\ Kátia Gardênia da Silva Coelho ${ }^{2}$ \\ Faculdade Católica Rainha do Sertão (FCRS)
}

\begin{abstract}
RESUMO:
A presente pesquisa tem por objetivo trabalhar o tema da liberdade na relação indivíduo e coletividade segundo o pensamento steiniano. Parte-se de uma investigação do indivíduo em relação consigo mesmo, com o outro para daí abstrair a essência da peculiaridade das influências externas do convívio do indivíduo na coletividade. Sendo assim, Stein analisa fenomenologicamente a pessoa humana em todas as suas dimensões e reconhece que é preciso averiguar as manifestações subjetivas da espiritualidade e examinar suas consequências na vida coletiva. Assim uma investigação fenomenológica sobre a relação indivíduo e coletividade está subjacente à problemática de se saber como o indivíduo pode resguardar sua individualidade e liberdade na convivência coletiva. Para responder essa questão a autora apresenta o caminho da fé como abertura para que o indivíduo possa agir eticamente, consciente na coletividade tendo em vista o bem comum. A liberdade humana como dom da graça e como condição humana que se revela através da relação entre o reino da natureza e o reino da graça.
\end{abstract}

PALAVRAS-CHAVES: Liberdade; Coletividade; Resguardo.

\section{ANALYSIS OF THE RELATIONSHIP THE INDIVIDUAL AND THE COLLECTIVITY SECOND EDITH STEIN}

\footnotetext{
${ }^{1}$ Doutor em Filosofia pela Universidade Estadual de Campinas (UNICAMP), São Paulo Brasil. Professor da Universidade Federal do Ceará (UFC), Ceará - Brasil. E-mail fabio.maia.sobral@gmail.com

${ }_{2}^{2}$ Mestre em Filosofia pela Universidade Estadual do Ceará (UECE), Ceará - Brasil. Bolsista da FUNCAP. Professora da Faculdade Católica Rainha do Sertão (FCRS), Ceará Brasil. E-mail: gardyinj@yahoo.com.br
} 


\begin{abstract}
:
The present research aims to work the theme of freedom in relation the individual and the collectivity second steiniano thought. It is part of a research of the individual in relation with himself, with the other for hence abstracting the essence of the peculiarity of external influences the conviviality of the individual in the collectivity. Thus, Stein phenomenologically analyzes all the dimensions of the human person and recognizes that it is necessary to investigate the subjective manifestations of spirituality and examine its consequences in collective life. Thus a phenomenological research about the relationship the individual and the collectivity is underlying the problem of how the individual can safeguard their individuality and freedom in collective coexistence. To answer this question the author presents the path of faith as opening so that the individual can act ethically, aware in collectivity in view of the common good. Human freedom as a gift of grace and as human condition that is revealed through the relation between the kingdom of nature and the Kingdom of grace.
\end{abstract}

KEYWORDS: Freedom; The collectivity; Overhead guard.

Stein em sua inquietação para compreender a verdade que explica o homem, situa em todas as suas obras o homem como ser livre. Na visão steiniana, razão e liberdade são parte constitutiva da pessoa. Sendo assim, a razão agrega-se à liberdade. $\mathrm{O}$ ser humano nasce para ser livre, porém, seguramente o que mais opõe resistência à liberdade é a própria natureza humana tão complexa. A autora afirma que a pessoa é livre diante de tudo, pois determina sua vida diante de si mesmo. Reconhecendo que o principal determinante para ser livre é o confronto consigo mesmo, com sua própria interioridade, pois é no mais profundo do ser que se encontra a liberdade.

$\mathrm{O}$ eu é o lugar que possibilita a pessoa humana aproximar-se de si mesmo e a faz tomar decisões que determinam a evolução do seu ser, onde as limitações e circunstâncias perdem o poder. Desse modo, a filósofa caminha na análise fenomenológica com a pretensão de descobrir a essência humana e leva à frente com o existencialismo, visto que o homem no pensamento steiniano não está sem sentido sobre o mundo. Mesmo assim é a sua natureza que coloca obstáculo ao sentido da sua existência.

Ao fazer $\mathrm{o}$ processo de saída da subjetividade para a intersubjetividade, o indivíduo toma consciência de sua individualidade e liberdade para um agir consciente no coletivo. A liberdade humana encontra sua plenitude no encontro com o ser divino - fonte da verdadeira liberdade, que se reconhece imagem e semelhança de Deus.

Uma análise da relação indivíduo e coletividade segundo Edith Stein - Fabio Maia Sobral; Kátia Gardênia da Silva Coelho. 


\begin{abstract}
A individualidade como a imagem que Deus mesmo leva em si de cada homem e segundo a Ele quer formá-lo, pertence aos mistérios que Deus mesmo há reservado e que não é possível a nenhum homem conhecer em totalidade. Nenhum homem nos conhece perfeitamente como somos e nós tão pouco nos conhecemos. Si se houverem que construir a meta educativa individual sobre um conhecimento perfeito da individualidade, então poderíamos abandonar desde o princípio nossa atividade educativa. Ele único caminho que seria capaz de uma educação para a meta individual, seria Deus (STEIN, 2003, p. 132).
\end{abstract}

A vivência que o homem faz com Jesus Cristo possibilita-lhe tornarse verdadeiramente humano, no sentido de ter clareza de firmes princípios e buscar comportar-se segundo tais princípios como: a bondade, a justiça e demais virtudes. Outro ponto de clareza é a capacidade em deixar-se ir a fundo, ao interior da alma humana, para daí captar a clareza da percepção de sua meta em concordância entre teoria e prática (STEIN, 2003, p. 69). Com isso surge o trabalho social em formar indivíduos para a vida coletiva. É na coletividade que o homem se humaniza no sentido de ver o outro como sujeito de experiência, que contribui para o reconhecimento de sua individualidade e liberdade, em meio à coletividade. A individualidade significa algo único em seu modo de ser independente e separado dos outros. Ao mesmo tempo, resguarda sua individualidade na diversidade da vida seja ela na sociedade, na comunidade ou no Estado, visto que é na vivência coletiva que o homem reconhece seus limites e sua individualidade imperfeita, que está sempre em processo de fazer-se (STEIN, 2003, p 2003). É na comunidade que o indivíduo desenvolve sua individualidade e liberdade.

A pessoa humana traz consigo ao mundo forças de sua natureza e de suas individualidades, que no curso de sua vida devem e querem desenvolver-se. Estas, somente podem desenvolver-se através da ação, e essa ação acontece principalmente sob a direção da comunidade, de homens em processo de desenvolvimento. "Um processo de desenvolvimento tem que conduzir à harmonia de suas forças individuais e sociais" (STEIN,2003, p 134).

O indivíduo é dotado de disposição comum humana e se relaciona com seus semelhantes, de tal maneira que se inicia um entendimento e uma vida coletiva, em que vive concretamente uma forma social. O indivíduo, porém, é dotado de uma disposição individual, uma peculiaridade única. $\mathrm{Na}$ coletividade o homem sente, pensa e trabalha em comum. A individualidade tem um significado positivo para a vida social na medida em que ela manifesta seu papel para que o indivíduo evolua humanamente. O indivíduo é livre e como ser livre usa de sua liberdade para a vida social, tendo como meta um agir ético na convivência coletiva. O indivíduo, entretanto, só pode usar de sua liberdade para uma ação ética na vida em 
comum a partir do momento em que se abre a Deus, pois só assim, o homem é capaz de viver em harmonia com seu semelhante (STEIN, 2003, p 139).

O homem busca por si mesmo seu caminho; cada um tem um objetivo distinto, e muitas vezes se cruzam os caminhos. Por conseguinte, observa o próximo, como pode servir para os seus próprios fins - como se faz com as coisas mortas, de acordo como converge, junta-se e ao mesmo tempo se opõe. Esta é a postura social medida racionalmente, dirigida para a utilidade prática.

Segundo Stein, quando o homem se afasta de Deus, ele também se afasta do seu próximo, no sentido de que age de acordo com suas inclinações naturais buscando seus próprios fins, gerando assim o individualismo em vez da individualidade. Sendo assim, surgem os conflitos entre indivíduo e comunidade, que causam efeitos trágicos sobre a vida prática. $\mathrm{O}$ individualismo acentua a vivência em grupos sociais que visam a utilização do indivíduo para seus interesses. Desse modo surge uma vida coletiva que esmaga a individualidade humana, descaracteriza o sujeito. Como consequência, o homem se desumaniza, perde sua individualidade na coletividade para dar lugar ao individualismo e ao socialismo.

$\mathrm{O}$ individualismo acentua somente o direito de o indivíduo livre desenvolver: não conhece nenhuma comunidade original e natural, mas somente grupos sociais, que servem a utilidade do indivíduo, e que vão sendo fundados por ele livremente com o fim de conseguir seus objetivos [...]. O ponto de vista contrário, que podemos chamar socialismo [...] ordena completamente o indivíduo na coletividade e a ela subordina; não reconhece nenhuma individualidade, mas somente a natureza humana em todas as partes iguais, e não consente vida fora da comunidade e sim ser útil para esta. (o socialismo que se nos propõe nos programas e na práxis de nosso partidos socialistas, não é um exemplo puro de tal concepção, já que se há desenvolvido historicamente a partir do liberalismo e, consequentemente, está fortemente entrelaçado com tendências individualistas). E assim observamos as consequências na falta d personalidades fortes e autônomas, empresas de grandes e originais, aproveitam os manufaturados e originais, e clichês, não somente em objetos de uso, mas também no setor intelectual: Pessoas de medíocres opiniões, - vazia e inautêntica sem caráter próprio, sem alma (STEIN, 2003, p.135).

Segundo Stein 2003, falsas teorias vão destruindo e conduz à enfermidade da vida social. Portanto, será necessário surgir uma teoria que possa resgatar a individualidade humana e isso se dá a partir de uma autêntica reflexão sobre os fundamentos eternos dos indivíduos e da comunidade (considerada como um tipo de vida coletiva) em se voltar ao princípio de uma abertura para o ser eterno. 
O indivíduo e a comunidade são queridos por Deus e fundados por Ele. A vida coletiva se constrói de indivíduos na diversidade. Sendo assim se um membro tende a prejudicar o outro está praticando um mal a todos os indivíduos, que fazem parte da comunidade. Disso resulta como reflexo da escolha por uma má inclinação, o mau uso da liberdade torna-se um perigo para que a individualidade seja sufocada na comunidade. Para isso é necessário ter um conhecimento de cada indivíduo com a intenção de promover a valorização da individualidade na vida social (STEIN, 2003, p.136). Um processo de desenvolvimento sadio tem como resposta a harmonia das forças individuais e sociais.

É preciso se fazer um trabalho que busque captar o elemento essencial da vida do homem. Com a intenção de captar aquilo que é característica da pessoa humana, não somente o fato de ter capacidade de raciocínio, mas algo que é muito mais amplo e inclui em si mesmo a racionalidade, isto é, a capacidade de sair de si mesmo, de transcender os limites da própria natureza física, e sua capacidade de acolher o outro. Portanto, há uma necessidade de trabalhar as más inclinações da própria natureza humana (violência, egoísmo, injustiça etc.) e levar o homem a compreender-se como um ser transcendente, como um ser que não se esgota em sua matéria e sensibilidade e que descobre, que não se encontra na realização de seu ser em si mesmo. A realização de si está na abertura para a realidade como manifestação da espiritualidade do homem que sai de si para o encontro com o outro, com o mundo e com o ser divino.

Desse modo, Stein compreende como unitário e tridimensional o ser humano: corpo-alma-espírito considerando como dimensões que definem a globalidade de seu ser. Isso mostra que a pessoa necessita estar em harmonia com todas as suas dimensões (corpo, alma e espírito), pois se a pessoa se descuida de uma dessas dimensões, não desenvolve sua plenitude de ser. E negligenciada a dimensão que caracteriza e unifica as demais, então o resultado é a insensatez e o vazio de sua existência (STEIN, 2003, p.41).

Para Stein a liberdade não se reduz simplesmente a uma capacidade de optar. A liberdade não é algo que simplesmente se dá, mas que Acima de tudo é uma conquista. O ser humano é livre na medida em que alcança e conquista seu ser, na medida em que se faz capaz de optar por aquilo que é melhor para si, aquilo que lhe aperfeiçoa (STEIN, 2003, p.41).

O tema da liberdade é para Stein essencial, pois sem a liberdade não há pessoa, visto que a liberdade é aquilo que define a pessoa como ser humano, é o que o diferencia dos outros seres. Esta liberdade não é apenas conquistada pela pessoa necessita de uma ação da graça para poder conquistar seu próprio centro, seu núcleo, o centro da liberdade para realizar atos livres. Entregar-se totalmente à vontade divina, já que o ser humano é limitado, e por suas próprias forças não consegue encontrasse no mais 
profundo de seu ser. É desta vivência profunda no íntimo de seu ser, onde a pessoa descobre sua individualidade e liberdade, e, busca a atitude ética, ou seja, procura conhecer e agir eticamente em prol do que é justo e correto, em sintonia com a vontade divina, para sair de si mesmo e ir ao encontro do outro na coletividade. A pessoa em harmonia com a vontade divina centrado no íntimo interior procura resguardar a liberdade e a individualidade na vida coletiva.

A antropologia steiniana tem por interesse a análise fenomenológica da individualidade e liberdade como pressupostos para uma atitude ética na coletividade procurando resguardar a individualidade e a liberdade, a partir do íntimo interior. Segundo Stein não é necessário o indivíduo ter plena consciência de que ao tomar uma decisão, de acordo com o que é justo e reto, esta seja consciente ou inconsciente agindo de acordo com a vontade divina, fonte de todo bem. O íntimo do interior é de onde emana a vontade de agir eticamente para o reto caminho em busca daquilo que seja bom para todos.

Para tanto é necessário que o homem tome uma decisão definitiva, e objetiva, que só podem provir do íntimo; assim, tal passagem equivale a uma completa transformação íntima, o que talvez seja impossível em termos naturais- é preciso haver um extraordinário reerguimento. Ninguém humanamente falando, é capaz de avaliar todas as razões pró ou contra que influem na decisão. Só há uma coisa a fazer: tomar a decisão de acordo com o que a consciência individual consiga discernir como melhor. [...] A consciência de quem vive compenetrado nessa certeza de Fé não se contentará com o que pessoalmente lhe parece melhor: há de procurar o que é certo aos olhos de Deus. Por aí é que somente a atitude religiosa é a verdadeira atitude ética ${ }^{3}$ (STEIN, 2004, p.138).

Segundo Stein é próprio do ser humano a procura pelo o que é correto, justo e bom. Contudo, a busca da decisão certa, revela a liberdade em Deus. Somente na harmonia com a vontade divina poderá discernir o que é justo e correto. E nessa harmonia da pessoa com o divino encontra-se a tomada de decisão livre sobre como agir eticamente que culmina na verdadeira liberdade humana. Desse modo, o homem possui em seu íntimo a marca do Eterno, fruto da vontade de querer o bem. Quer o homem saiba ou não, que Deus habita no íntimo de seu ser quando busca a prática do bem.

Quem procura o que é certo, e toma decisões de acordo com seu entendimento, encontra-se a caminho de Deus e de si próprio, ainda que não saiba. Mas não tem ainda o pleno domínio sobre si, o qual é fruto da penetração no íntimo interior [...]. Por essa razão a pessoa que compenetrou em seu

${ }^{3}$ STEIN, E. A ciência da cruz: estudos sobre São João da Cruz. São Paulo: Loyola, 2004, p. 138. 
íntimo interior não poderá dispor da plenitude das disposições de si mesmo e nem da plenitude livre de suas decisões porque faltará acolher a vontade divina fonte da verdadeira liberdade e de todo bem. "Quem procura por princípio o que é reto, isto é, quem tiver a vontade de praticá-lo em todas as circunstâncias, decidiu sobre si mesmo e entregou a sua vontade à vontade de Deus, mesmo que não veja com clareza que a prática do que é reto coincide com a vontade divina (STEIN, 2004, p.139).

A experiência da passagem da subjetividade para a intersubjetividade, isto é, sair de si para o reconhecimento da alteridade do outro, é a empatia. A empatia é fundamento para o ser humano ver o outro como sujeito de experiência e não como objeto. A atitude do indivíduo vai depender de como se situa frente ao outro, atuar em prol do bem comum. "Assim, ela se torna a empatia como a fundamento da experiência intersubjetiva, possibilidade de um conhecimento do estado existente mundo externo" (STEIN, 2005, p.146). É a partir da experiência intersubjetiva, com o outro, que o indivíduo compreende a si mesmo, toma consciência de sua verdadeira individualidade e liberdade, para atuar eticamente na vida coletiva.

A empatia não aparece neste contexto como um constituinte, mas apenas como um importante meio auxiliar para a detenção do próprio indivíduo (ao contrário do corpo vivo próprio a compreensão como um corpo físico com outro, que não seria possível sem empatia). E, como tal, meio auxiliar também é mostrado do outro lado. [...] É possível que outro me jugue melhor que eu próprio e me fornece maior claridade sobre mim mesmo. Ele observou, por exemplo, que eu olho em volta de mim procurando aprovação quando eu faço o bem, enquanto eu próprio acredito trabalhar por pura misericórdia. Então eles trabalham em conjunto, empatia e percepção interna para darme eu a mim mesmo. (STEIN, 2005, p.172).

Os atos sentimentais nos quais se descobrem os estratos pessoais pertencentes aos sentimentos do amor, do ódio, da gratuidade são elementos que se expressam pelo fato de voltar-se para o outro. Entretanto estes sentimentos localizam-se em diferentes formas no eu (psíquico). O sentimento do amor, porém, é o afeto mais profundo. Desse modo, os atos dos sentimentos geram um voltar-se para o outro, na medida em que, é construtivo da pessoa mesma que apreende do outro. Isso realiza um valor, o querer o bem ao outro, o ato de amar, pois é um valor derivado do próprio indivíduo, que realiza e apreende outros valores que é o dar-se em atos mais profundos. Quando se ama uma pessoa, reconhece-se o valor pelo que a pessoa é por ela mesma, e não pelo bem que ela faz. E desse valor, o amor se exterioriza, e se radica na profundidade do valor da moral, pelo qual se expressa a vivência do valor para ação. 
Stein chama de raio de ação a profundidade e intensidade de um sentimento, que se submete às leis racionais. $\mathrm{O}$ raio de ação faz parte da estrutura da pessoa expressando na vontade de querer realizar o bem. "Compreender uma ação significa, portanto, não só satisfazer seu ser empático como experiência singular, mas vivenciá-la totalmente a partir da estrutura total da pessoa" (STEIN, 2005, p.195). Esta estrutura total da pessoa implica nas dimensões do ser humano, como pessoa espiritual, que se compreende na análise fenomenológica das seguintes formas: na dimensão da origem de seus atos, na dimensão da qualidade da individualidade, na dimensão social cultural. A pessoa, na dimensão individual, encontra-se no nível mais profundo, no íntimo da alma. O núcleo, a pessoa, na dimensão social engloba-se nas relações sociais tais como: comunidade, sociedade e Estado.

Por último, tem-se a dimensão religiosa da pessoa humana. Nela o ser humano se percebe fenomenologicamente na religião, isto é, vista como manifestação que expressa eticamente nas atitudes das relações humanas buscando resguardar a individualidade e a liberdade na vida coletiva. Esta dimensão religiosa também é vista como destino último para uma compreensão de aproximação plena que se dá somente com a revelação divina, sendo assim, conhece-se a interioridade mais profunda da alma como a morada de Deus.

Cada alma individual tem saído das mãos de Deus e leva uma marca particular. [...] Este ser está escondido pelo caráter que recebe nele a natureza humana no curso de sua vida, sob influência do mundo que o rodeia e em especial das relações recíprocas na sociedade. O que a alma pode sentir deste ser original nela mesma e no outro fica obscuro e cheio de mistério (STEIN, 1994, p.519).

A compreensão de uma antropologia steiniana segue um caminho ético que se fundamenta com o seguimento de Deus, Cristo. O que tem a ver com a sua posição de filosofia cristã. A ética então se confunde com a mística. O ato ético fundamental ou opção fundamental é a escolha por Deus, é a busca da tomada de decisão pelo que é certo e justo, que só alcança com a ajuda da ação da graça divina que culmina na liberdade, fruto do mais íntimo interior.

Sendo assim Stein a análise fenomenológica para compreender a pessoa humana em todas as suas dimensões reconhece que é preciso averiguar as manifestações subjetivas da espiritualidade e examinar suas consequências na vida coletiva, seja na comunidade, na sociedade ou no Estado. Neste sentido uma investigação fenomenológica sobre a relação indivíduo e comunidade está subjacente à problemática de se saber como indivíduo pode resguardar sua individualidade e liberdade na convivência coletiva. Para responder essa questão a autora apresenta o caminho da fé 
como abertura para que o indivíduo possa agir eticamente consciente na coletividade tendo em vista o bem comum. Quando o indivíduo acolhe a vontade divina haverá realizado com liberdade o que é correto e justo, acham-se incluídas todas as futuras decisões que por si mesmas se realizam em cada momento determinado de suas experiências com os outros. Segundo Stein cada pessoa possui dentro de si um raio de ação em desejar realizar o bem.

A individualidade tem sua marca positiva para a vida social, na medida em que ela aponta qual deve ser o papel da pessoa tanto na vida comunitária como no âmbito da evolução humana. A vida humana é coletiva, apesar de cada indivíduo possuir sua singularidade e individualidade própria. A saída dessa subjetividade para a intersubjetividade é o que sustenta uma convivência comunitária. Tal convivência é fruto do reconhecimento do outro que se dá na condição de estar-com o outro respeitando a liberdade na coletividade. A descoberta do autêntico sentido da vida perpassa pela abertura do homem ao ser Eterno.

O resultado disso é um fecundo viver autenticamente humano sobre um constante processo de humanização do ser humano que se dá na convivência social. A sociedade como espaço de convivência possibilita o homem a ver o mundo como um campo de ação e se sente impelido a trabalhar para transformar este mundo por ação própria, em vista do bem comum. Enquanto que o Estado cumpre o papel de possibilitar os meios necessários para que o indivíduo possa desenvolver um objetivo de comunidade ética.

A partir da questão da liberdade, em meio à coletividade, vê-se como o indivíduo consegue, diante das relações comunitárias, sociais e políticas resguardar sua liberdade, ou mais propriamente a sua individualidade, e atuar de forma consciente procurando pensar no coletivo. Partindo desse contexto verifica-se a importância do papel do Estado para a vida do indivíduo em comunidade. Stein rejeita a concepção de que o Estado exerça a responsabilidade pela liberdade da pessoa, ou seja, o Estado cria os meios para que o indivíduo tenha as condições necessárias para atuar de forma livre na sociedade, pois não é o Estado quem cria a liberdade do homem; a liberdade faz parte do indivíduo, do seu interior, no núcleo da pessoa humana. O Estado tem sua razão de ser para legislar e proteger o sujeito que vive em sociedade. Dois pontos a serem destacados nesse capítulo tratam da questão do núcleo da pessoa humana, que designa a essência da pessoa considerada como fator qualitativo indissolúvel em que se encontram todos os seus possíveis processos evolutivos.

O núcleo da pessoa humana é lugar onde está a marca da vivência do indivíduo, aquilo que o diferencia das demais pessoas e pelo qual desvela no sujeito o mundo dos valores. O último ponto toca justamente a problemática sobre a individualidade e a liberdade; na coletividade Stein vai destacar como chave para a resolução do problema, como o indivíduo consegue 
resguardar sua individualidade, mais propriamente, a liberdade na vida coletiva, seja na sociedade ou na comunidade. A autora põe em evidência a importância do conhecimento de si mesmo e a experiência do outro como ferramenta para que o indivíduo possa exercer sua liberdade na coletividade. A experiência do outro contribui para o conhecimento de si e assim ter consciência de sua liberdade, respeitando as semelhanças e diferenças na convivência coletiva, para um atuar dotado de vontade ética que busque resguardar a individualidade e liberdade na coletividade.

\section{Referências bibliográficas}

STEIN, Edith. Obras Completas. Vol. IV. Escritos antropológicos y pedagógicos: magistério de vida cristiana, 1926-1933. Trad. de Francisco Javier Sancho, OCD. José Mardomingo, Constantino Ruiz Garrido, Carlos Días, Alberto Pérez, OCD. Gerlinde Follrich de Aginaga. Madri: Monte Carmelo, 2003.

Obras Completas. Vol. V. Escritos espirituales: en el Carmelo Teresiano: 1933-1942.Trad. de Francisco Javier Sancho, ODC, Julen Urkiza, OCD. Madrid: Monte Carmelo, 2004. . A ciência da cruz. 4 ed. São Paulo: Loyola, 2004.

Obras Completas. Vol. II. Escritos filosóficos: etapa fenomenológica: 1915-1920. Tradução do Alemão de Constantino Ruiz Garrido, José Luis Callero Boro. Madrid: Monte Carmelo, 2005.

\section{Contribuição dos autores:}

Os autores Fabio Maia Sobral e Kátia Gardênia da Silva Coelho participaram da discussão, revisão e redação do artigo. Todos os autores aprovaram a versão final do texto. 